ARTICLE

\title{
Enhancing carbon dioxide gas-diffusion electrolysis by creating a hydrophobic catalyst microenvironment
}

\author{
Zhuo Xing (iD ${ }^{1,2}$, Lin $\mathrm{Hu}^{3}$, Donald S. Ripatti ${ }^{4}$, Xun Hu (D) ${ }^{1 凶}$ \& Xiaofeng Feng (iD) ${ }^{2,3,5 凶}$
}

Electroreduction of carbon dioxide $\left(\mathrm{CO}_{2}\right)$ over copper-based catalysts provides an attractive approach for sustainable fuel production. While efforts are focused on developing catalytic materials, it is also critical to understand and control the microenvironment around catalytic sites, which can mediate the transport of reaction species and influence reaction pathways. Here, we show that a hydrophobic microenvironment can significantly enhance $\mathrm{CO}_{2}$ gasdiffusion electrolysis. For proof-of-concept, we use commercial copper nanoparticles and disperse hydrophobic polytetrafluoroethylene (PTFE) nanoparticles inside the catalyst layer. Consequently, the PTFE-added electrode achieves a greatly improved activity and Faradaic efficiency for $\mathrm{CO}_{2}$ reduction, with a partial current density $>250 \mathrm{~mA} \mathrm{~cm}^{-2}$ and a single-pass conversion of $14 \%$ at moderate potentials, which are around twice that of a regular electrode without added PTFE. The improvement is attributed to a balanced gas/liquid microenvironment that reduces the diffusion layer thickness, accelerates $\mathrm{CO}_{2}$ mass transport, and increases $\mathrm{CO}_{2}$ local concentration for the electrolysis.

\footnotetext{
${ }^{1}$ School of Material Science and Engineering, University of Jinan, Jinan, China. ${ }^{2}$ Department of Physics, University of Central Florida, Orlando, FL, USA.

${ }^{3}$ Department of Materials Science and Engineering, University of Central Florida, Orlando, FL, USA. ${ }^{4}$ Polymers Science and Material Chemistry, Exponent Inc, Menlo Park, CA, USA. ${ }^{5}$ Renewable Energy and Chemical Transformations (REACT) Cluster, University of Central Florida, Orlando, FL, USA.

凶email: mse_hux@ujn.edu.cn; Xiaofeng.Feng@ucf.edu
} 
$\mathrm{B}$ ecause of the limited reserves of fossil fuels, there is a rising demand for renewable energy technologies that can reduce our dependence on fossil fuels and address the anthropogenic climate change ${ }^{1}$. A promising approach is to power the synthesis of fuels and chemicals from naturally abundant resources using renewable electricity ${ }^{2}$. Such electrosynthesis processes are compatible with the intermittent supply of electricity from renewable resources, such as solar or wind, and can enable sustainable production of fuels and chemicals ${ }^{3}$. Accordingly, numerous efforts have been made to develop efficient electrocatalysts for the conversion of $\mathrm{CO}_{2}, \mathrm{CO}, \mathrm{N}_{2}$, and $\mathrm{H}_{2} \mathrm{O}$ to valuable chemicals, such as hydrocarbons, oxygenates, and ammonia ${ }^{4-12}$. In particular, the electrochemical reduction of $\mathrm{CO}_{2}$ over $\mathrm{Cu}$-based catalysts has received considerable interest, because $\mathrm{Cu}$ exhibits appreciable activity for $\mathrm{C}-\mathrm{C}$ coupling to form multicarbon products, including ethylene, ethanol, and propanol $^{13,14}$. While efforts are focused on developing catalytic materials, it is also critical to understand other factors beyond catalytic materials, such as the local environment of the catalysts ${ }^{15}$, which can mediate the transport and local concentration of reaction species and influence reaction pathways ${ }^{16}$.

Electrochemical $\mathrm{CO}_{2}$ reduction reaction $\left(\mathrm{CO}_{2} \mathrm{RR}\right)$ has been typically evaluated using $\mathrm{H}$-type cells $(\mathrm{H} \text {-cells })^{6-8}$, where the electrode is immersed in liquid electrolyte, and $\mathrm{CO}_{2}$ molecules dissolve in the electrolyte and diffuse down a concentration gradient to the catalyst surface for reactions ${ }^{9}$, as schematically shown in Fig. 1a. While this cell configuration works well for evaluating $\mathrm{CO}_{2} \mathrm{RR}$ at low current densities ${ }^{6-10}$, the low solubility and slow diffusion of $\mathrm{CO}_{2}$ in the electrolyte will cause a mass transport limitation at high current densities. The limiting current density for $\mathrm{CO}_{2} \mathrm{RR}$ on a planar electrode can be estimated by: $j_{\text {lim }}=n F D_{0} C_{0} / \delta$, where $n$ is the number of electrons transferred in the reaction, $F$ is the Faraday constant, $D_{0}$ and $C_{0}$ are the diffusion coefficient and solubility of $\mathrm{CO}_{2}$ in the electrolyte, and $\delta$ is the diffusion layer thickness. The diffusion layer is a virtual layer of the $\mathrm{CO}_{2}$ concentration gradient interval ${ }^{17}$, which extends from the electrode surface to the point where the concentration of $\mathrm{CO}_{2}$ reaches the bulk concentration, as illustrated in Supplementary Fig. 1. Typically, the diffusion layer thickness is of the order of magnitude of $100 \mu \mathrm{m}$ for $\mathrm{CO}_{2} \mathrm{RR}$ in $\mathrm{H}$-cell ${ }^{18}$, resulting in a limiting current density of the order of $10 \mathrm{~mA} \mathrm{~cm}^{-2}$, as indicated by the estimation in Supplementary Fig. 1.

To alleviate the limitations of mass transport, flow cells with gas-diffusion electrodes (GDEs) have been developed and used to investigate electrochemical $\mathrm{CO}_{2}$ or $\mathrm{CO}$ reduction ${ }^{19-28}$. A GDE typically consists of a carbon fiber paper (CFP), a microporous layer (MPL), and a catalyst layer ${ }^{20}$. The catalyst side of a GDE is in contact with the electrolyte and the other side is exposed to flowing reactant gas, which diffuses through the pores in the CFP to reach the catalyst, as schematically illustrated in Fig. 1b. The MPL is composed of carbon powder and polytetrafluoroethylene (PTFE) particles, which can maintain the separation of the liquid and gas phases to prevent flooding of the pores in the CFP20. The catalyst particles in a GDE are often wetted by electrolyte due to their lack of hydrophobicity, as a result the reaction occurs primarily in aqueous phase via dissolved $\mathrm{CO}_{2}$ (refs. ${ }^{29-31}$ ). In this cell configuration, reactant molecules diffuse through a relatively thin layer of electrolyte to reach the catalyst ${ }^{29,30}$, which greatly reduces the diffusion layer thickness and enables high-rate $\mathrm{CO}_{2}$ electrolysis at current densities $>200 \mathrm{~mA} \mathrm{~cm}^{-2}$, as indicated by the plot in Supplementary Fig. 1. Nevertheless, the catalyst layer typically has a thickness of at least a few micrometers ${ }^{18}$, so the $\mathrm{CO}_{2} \mathrm{RR}$ may still be limited by $\mathrm{CO}_{2}$ mass transport inside the three-dimensional catalyst layer ${ }^{32}$.

Furthermore, the greatly improved $\mathrm{CO}_{2} \mathrm{RR}$ performance in GDE cells was also attributed to local gaseous environment and three-phase interfaces between solid catalyst, liquid electrolyte, and gaseous $\mathrm{CO}_{2}$ in some studies ${ }^{21,22}$. However, such argument remains under debate, that is, whether the $\mathrm{CO}_{2} \mathrm{RR}$ in a GDE cell can occur at a solid-liquid-gas interface via gaseous $\mathrm{CO}_{2}$, in contrast to the conventional electrode-electrolyte interface ${ }^{29}$. Recently, a few studies explored the three-phase interfaces for $\mathrm{CO}_{2}$ or $\mathrm{CO}$ reduction in $\mathrm{H}$-cells ${ }^{33-38}$, typically using a hydrophobic substrate for the electrode. Although the electrode was immersed in liquid electrolyte in an H-cell, the hydrophobic substrate might trap gaseous reactant near the catalyst layer to change the local environment and form solid-liquid-gas interfaces, which could improve the activity and selectivity for $\mathrm{CO}_{2}$ or a
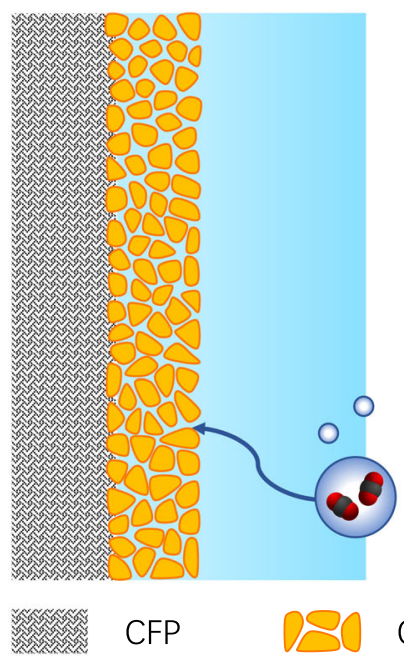

$89 \mathrm{BPL}$ b

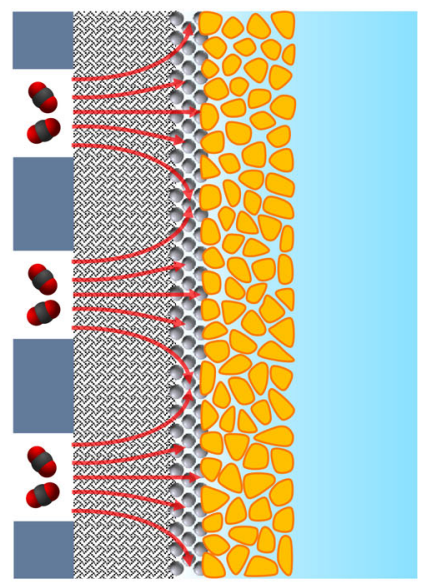

Cu particles

PTFE particles
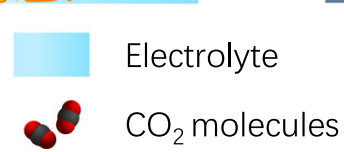

C

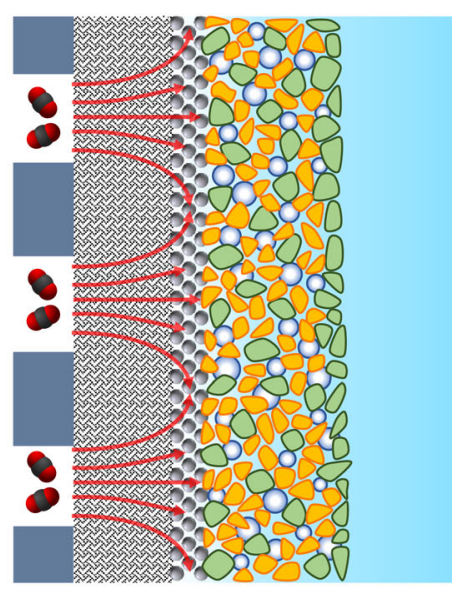

Gas flow

$\mathrm{CO}_{2}$ bubbles

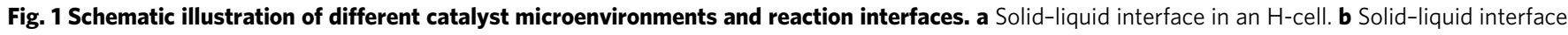
in a regular GDE cell. c Proposed hydrophobic microenvironment with solid-liquid-gas interfaces that can be constructed in a GDE cell by dispersing PTFE nanoparticles inside the catalyst layer. 
CO reduction ${ }^{34-36}$. These studies revealed the significant impact of the local gas/liquid environment of the catalysts in gasinvolving electrochemical reactions ${ }^{38}$. However, much remains to be understood regarding the catalyst microenvironment and reaction interfaces, such as how to create an optimal microenvironment with solid-liquid-gas interfaces, and how such an environment affects the mass transport and kinetics of electrocatalytic reactions.

Here, we present a study of a hydrophobic microenvironment with solid-liquid-gas interfaces for gas-involving electrocatalysis, particularly $\mathrm{CO}_{2}$ reduction on $\mathrm{Cu}$ catalyst. As a proof-of-concept, we select commercially available $\mathrm{Cu}$ nanoparticles as the catalyst, so that the conclusions do not rely on any specially designed catalyst and can be generally applicable. We first show that using a hydrophobic substrate for the electrode improves the activity and selectivity for $\mathrm{CO}_{2} \mathrm{RR}$ in $\mathrm{H}$-cell, validating the impact of the local environment. Then we design a GDE with a hydrophobic catalyst microenvironment for $\mathrm{CO}_{2}$ gas-diffusion electrolysis by dispersing PTFE nanoparticles in the catalyst layer, where the hydrophobic PTFE can repel liquid electrolyte and maintain gaseous reactant near the catalyst particles, as schematically shown in Fig. 1c. As a result, this electrode shows a significant improvement in the activity and Faradaic efficiency for $\mathrm{CO}_{2} \mathrm{RR}$ as compared to regular GDEs without added PTFE. The improved catalytic performance is attributed to a balanced gas/liquid microenvironment that reduces the diffusion layer thickness, and enhances the mass transport and kinetics of $\mathrm{CO}_{2}$ electrolysis, providing a general approach to improve gas-involving electrocatalysis.

\section{Results}

Characterization of $\mathrm{Cu}$ nanocatalyst. Commercial $\mathrm{Cu}$ nanoparticles (see Supplementary Note 1) were used as the electrocatalyst for $\mathrm{CO}_{2} \mathrm{RR}$ in this study. The $\mathrm{Cu}$ catalyst is less active than those specially designed $\mathrm{Cu}$ catalysts ${ }^{19-22}$, but it is widely available and often used as a reference sample in $\mathrm{CO}_{2} \mathrm{RR}$ studies ${ }^{19,21}$. The nanoparticles were characterized by transmission electron microscopy (TEM), X-ray diffraction (XRD), and X-ray photoelectron spectroscopy (XPS) to examine their size and composition, as presented in Supplementary Fig. 2. The TEM images and derived particle size distribution revealed an average size of $47.9 \pm$ $16.8 \mathrm{~nm}$ of the $\mathrm{Cu}$ nanoparticles. XRD pattern showed diffraction peaks of $\mathrm{Cu}$ and a small fraction of $\mathrm{Cu}_{2} \mathrm{O}$, of which the latter was due to oxidation by air. XPS survey spectrum showed mainly $\mathrm{Cu}$ and $\mathrm{O}$ peaks, where the $\mathrm{O}$ was attributed to the $\mathrm{Cu}_{2} \mathrm{O}$ component. To further identify the chemical state of the $\mathrm{Cu}$ catalyst during $\mathrm{CO}_{2} \mathrm{RR}$, operando X-ray absorption spectroscopy (XAS) characterization was performed, as shown in Supplementary Fig. 3, and the acquired $\mathrm{Cu} \mathrm{K}$-edge XAS spectra indicated that the catalyst was reduced to metallic $\mathrm{Cu}$ state under $\mathrm{CO}_{2} \mathrm{RR}$ conditions ${ }^{39}$.

Microenvironment for $\mathbf{C O}_{2} \mathbf{R R}$ in $\mathbf{H}$-cell. We first examined the microenvironment for $\mathrm{CO}_{2} \mathrm{RR}$ on the $\mathrm{Cu}$ catalyst in $\mathrm{H}$-cell, where a simple model of solid-liquid interface can be used to describe the reaction interface (Fig. 1a). To probe the effect of substrate hydrophobicity on the electrode performance, two substrates purchased from the Fuel Cell Store were used for comparison: AvCarb MGL370 CFP, and AvCarb GDS2230 consisting of CFP and a hydrophobic MPL coating. Contact angle measurements on them (Supplementary Fig. 4) revealed superior hydrophobicity of the AvCarb GDS2230 (151.7 $\left.{ }^{\circ}\right)$ relative to the MGL370 $\left(119.0^{\circ}\right)$. Electrodes were prepared by depositing the catalyst ink (a mixture of $\mathrm{Cu}$ nanoparticles and carbon black) on the two substrates, and their configurations are schematically shown in Fig. 2a. Scanning electron microscopy (SEM) images suggested that the morphology of the catalyst layers on the two substrates was very similar
(Supplementary Fig. 5). $\mathrm{CO}_{2} \mathrm{RR}$ tests were performed in an $\mathrm{H}$-cell with $\mathrm{CO}_{2}$ gas bubbling into the cathodic compartment (Supplementary Fig. 6). The $\mathrm{CO}_{2} \mathrm{RR}$ performance was evaluated by controlled potential electrolysis in $1 \mathrm{M} \mathrm{KHCO}_{3}$ electrolyte. All potentials were reported with respect to the reversible hydrogen electrode (RHE) in this study. Gas-phase products were quantified by periodic gas chromatography, and solution-phase products were analyzed at the end of each electrolysis by nuclear magnetic resonance (NMR) spectroscopy (Supplementary Fig. 7).

$\mathrm{CO}_{2} \mathrm{RR}$ was first evaluated at various potentials ranging from -0.5 to $-1.0 \mathrm{~V}$ vs RHE for both electrodes, and representative chronoamperometric curves are shown in Supplementary Fig. 8. As expected, the partial current density for $\mathrm{CO}_{2} \mathrm{RR}$ increased exponentially with the overpotential for both electrodes (Fig. 2b). Interestingly, the $\mathrm{CO}_{2} \mathrm{RR}$ current densities on the GDS2230 electrode were generally higher than that on the MGL370 electrode, particularly at higher overpotentials. For example, a $\mathrm{CO}_{2} \mathrm{RR}$ current density of $\sim 23 \mathrm{~mA} \mathrm{~cm}^{-2}$ was reached at $-1.0 \mathrm{~V}$ on the GDS2230 electrode, which is about four times that on the MGL370 electrode $\left(\sim 6 \mathrm{~mA} \mathrm{~cm}^{-2}\right)$. As there was no major difference between the two electrodes regarding the morphology (Supplementary Fig. 5) or the conductivity (as revealed by the electrochemical impedance spectra (EIS) in Supplementary Fig. 9), their difference in $\mathrm{CO}_{2} \mathrm{RR}$ performance is attributed to the substrate hydrophobicity, most likely because the hydrophobic MPL can repel liquid electrolyte and trap gas bubbles ${ }^{40,41}$.

To verify the liquid repelling effect of the MPL, we measured the contact angles of the AvCarb MGL370 and GDS2230 substrates (no catalyst loading) after electrochemical treatment at $-1.0 \mathrm{~V}$ in the electrolyte. As shown in Supplementary Fig. 4, the contact angle of the MGL370 substrate dropped significantly from $119.0^{\circ}$ to $22.5^{\circ}$ due to electrochemical modifications. In contrast, the GDS2230 substrate remained similarly hydrophobic with a contact angle of $\sim 150^{\circ}$ after the treatment, so the MPL cannot be wetted or flooded by the electrolyte and gas bubbles can be maintained in the pores of the MPL. When the GDS2230 electrode is tested for $\mathrm{CO}_{2} \mathrm{RR}$, the gas bubbles trapped inside the MPL can serve as an intermediate reservoir of gaseous $\mathrm{CO}_{2}$ for the reaction. Thus, the diffusion layer thickness decreases to the distance between the gas bubbles in the MPL and the catalyst particles ${ }^{42}$, which improves $\mathrm{CO}_{2}$ mass transport to the catalyst layer and increases the $\mathrm{CO}_{2} \mathrm{RR}$ limiting current density. This is also supported by the potentialdependent difference in the $\mathrm{CO}_{2} \mathrm{RR}$ performance between the two electrodes: the $\mathrm{CO}_{2} \mathrm{RR}$ current density was similar at $-0.5 \mathrm{~V}$, but the difference was enlarged to 4 -fold at $-1.0 \mathrm{~V}$ where the $\mathrm{CO}_{2} \mathrm{RR}$ became limited by mass transport (Fig. 2b), confirming that $\mathrm{CO}_{2}$ mass transport in the GDS2230 electrode is improved by the MPL. This mechanism can also explain the enhanced performance for $\mathrm{CO}$ reduction on hydrophobic electrodes ${ }^{35,36}$.

How is gaseous $\mathrm{CO}_{2}$ formed in the MPL? It can be formed directly by trapping the purged $\mathrm{CO}_{2}$ gas bubbles ${ }^{34}$, or indirectly from the dissolved $\mathrm{CO}_{2}$ molecules in the electrolyte ${ }^{43}$. If it is the former case, the gas bubbling rate will affect the trapping of gaseous $\mathrm{CO}_{2}$ and the $\mathrm{CO}_{2} \mathrm{RR}$ rate ${ }^{34}$; otherwise the $\mathrm{CO}_{2} \mathrm{RR}$ rate should not depend on the gas bubbling rate in the latter case, as long as the electrolyte remains saturated with $\mathrm{CO}_{2}$. In the $\mathrm{H}$-cell, the electrode is positioned $\sim 1 \mathrm{~cm}$ away from the gas inlet (Supplementary Fig. 6), so it is less likely to directly trap gas bubbles. We varied the $\mathrm{CO}_{2}$ gas bubbling rate to examine the gas trapping by the MPL. Figure $2 \mathrm{c}$ shows the $\mathrm{CO}_{2} \mathrm{RR}$ current density measured on the two electrodes at $-1.0 \mathrm{~V}$ with various $\mathrm{CO}_{2}$ gas bubbling rates, ranging from 2 to 6 standard cubic centimeters per minute $(\mathrm{sccm})$. Both current densities remained largely unchanged with the bubbling rate, indicating that the $\mathrm{CO}_{2} \mathrm{RR}$ mainly relied on the dissolved $\mathrm{CO}_{2}$ molecules for both electrodes. We postulate that the hydrophobic MPL can facilitate the 
a

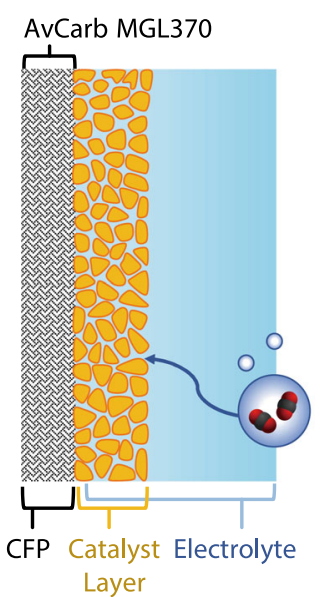

C

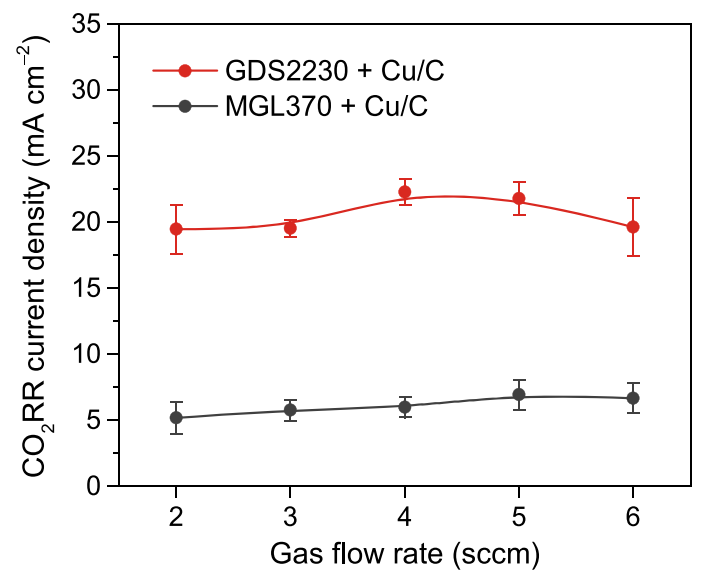

b
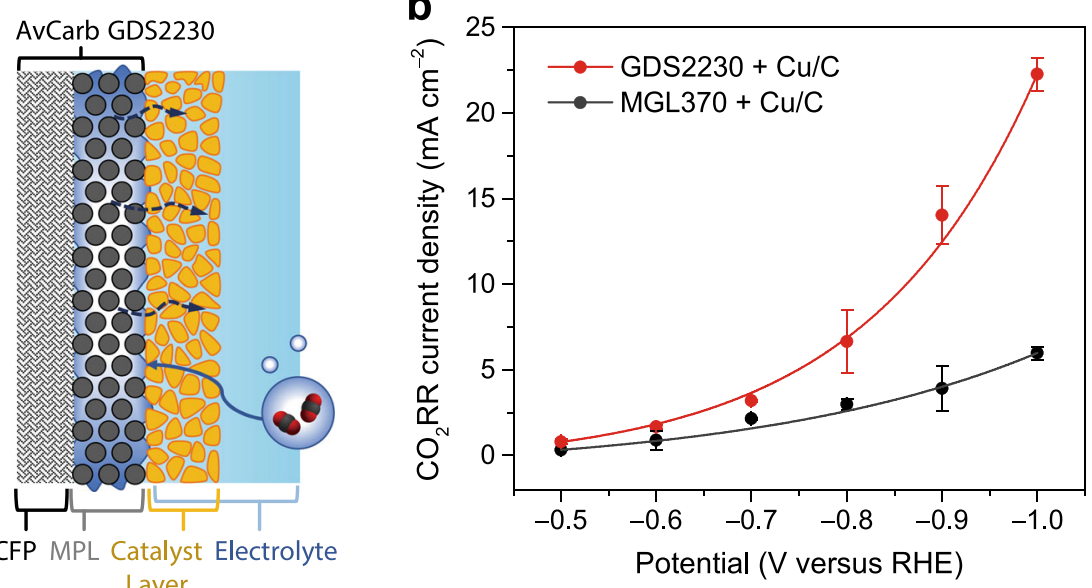

d
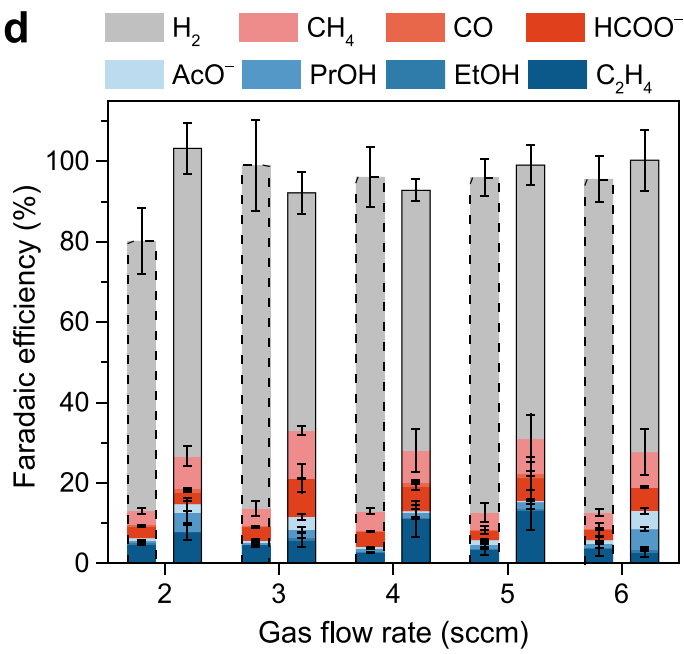

Fig. 2 Effect of hydrophobic substrate on the $\mathbf{C O}_{\mathbf{2}} \mathbf{R R}$ in $\mathbf{H}$-cell. a Configurations of the two electrodes prepared with AvCarb MGL370 and GDS2230 substrates. b Partial current densities for $\mathrm{CO}_{2} \mathrm{RR}$ on the two electrodes at various potentials with a $\mathrm{CO}_{2}$ gas flow rate of $4 \mathrm{sccm}$. $\mathbf{c}$ Partial current densities and $\mathbf{d}$ Faradaic efficiencies for $\mathrm{CO}_{2} \mathrm{RR}$ on the two electrodes at $-1.0 \mathrm{~V}$ with various $\mathrm{CO}_{2}$ flow rates. In $\mathbf{d}$, the left column with dashed line frame at each flow rate is for the AvCarb MGL370 + Cu/C electrode, and the right column with solid line frame is for the AvCarb GDS2230 + Cu/C electrode. The error bars represent the standard deviation of three independent measurements.

nucleation and formation of $\mathrm{CO}_{2}$ gas bubbles from the $\mathrm{CO}_{2^{-}}$ saturated electrolyte ${ }^{44}$. Similarly, the Faradaic efficiency for $\mathrm{CO}_{2} \mathrm{RR}$ also showed a weak dependence on the gas flow rate (Fig. 2d). The total Faradaic efficiency for $\mathrm{CO}_{2} \mathrm{RR}$ on the GDS2230 and MGL370 electrodes was $\sim 30 \%$ and $13 \%$, respectively. We attribute the difference to a higher local concentration of $\mathrm{CO}_{2}$ due to the improved mass transport by the MPL ${ }^{34}$. The difference in the $\mathrm{CO}_{2} \mathrm{RR}$ selectivity confirmed the impact of the electrode hydrophobicity and corresponding local environment on the $\mathrm{CO}_{2} \mathrm{RR}$.

Hydrophobic microenvironment for $\mathrm{CO}_{2} \mathrm{RR}$ in GDE cell. It was shown above that a hydrophobic substrate can change the local gas/liquid environment and improve the mass transport for $\mathrm{CO}_{2} \mathrm{RR}$ in an $\mathrm{H}$-cell. In a GDE cell, the catalyst layer typically has a thickness of at least a few micrometers ${ }^{18,32}$, so the MPL is unlikely to influence the microenvironment deep inside the catalyst layer. Therefore, we designed an electrode with local hydrophobic centers by dispersing PTFE particles inside the catalyst layer, where the PTFE can repel liquid electrolyte and maintain gas bubbles in neighboring pores, as schematically shown in Fig. 1c. In particular, PTFE nanoparticles of 30-40 nm in size (Nanoshel LLC) were used, which have a similar size as the
$\mathrm{Cu}$ nanoparticles and can enable a uniform mixing, as verified by the energy-dispersive X-ray spectroscopy (EDS) elemental mapping in Supplementary Fig. 10. Thus, the PTFE nanoparticles can trap numerous gas bubbles in the catalyst layer and enforce a high surface area gas-liquid interface near the catalyst particles during $\mathrm{CO}_{2} \mathrm{RR}$.

To understand the effect of the hydrophobic microenvironment, two electrodes were prepared for comparison: one using the original catalyst ink ( $\mathrm{Cu}$ nanoparticles and carbon black), and the other using PTFE-dispersed catalyst ink with a 50\% mass ratio of PTFE, both deposited on the AvCarb GDS2230 substrate. The two electrodes have the same loading of $\mathrm{Cu}$ nanoparticles, and they are referred as $\mathrm{Cu} / \mathrm{C}$ and $\mathrm{Cu} / \mathrm{C} / \mathrm{PTFE}$ electrodes, respectively. SEM images indicated that the morphology of the catalyst layers of the two electrodes was very similar (Supplementary Fig. 11). $\mathrm{CO}_{2}$ gas-diffusion electrolysis was tested using a home-built GDE flow cell (Supplementary Fig. 12) with circulating $1 \mathrm{M} \mathrm{KOH}$ electrolyte (Supplementary Fig. 13). The electrodes were first evaluated at various potentials, ranging from -0.5 to $-1.0 \mathrm{~V}$. As shown in Fig. 3a, the partial current density for $\mathrm{CO}_{2} \mathrm{RR}$ on the $\mathrm{Cu} / \mathrm{C}$ electrode increased from $39 \mathrm{~mA} \mathrm{~cm}^{-2}$ at $-0.5 \mathrm{~V}$ to $138 \mathrm{~mA} \mathrm{~cm}^{-2}$ at $-1.0 \mathrm{~V}$, much higher than that measured for the same electrode in the H-cell (Fig. 2b). The $\mathrm{Cu}$ / $\mathrm{C} / \mathrm{PTFE}$ electrode showed an even higher $\mathrm{CO}_{2} \mathrm{RR}$ current density 
a

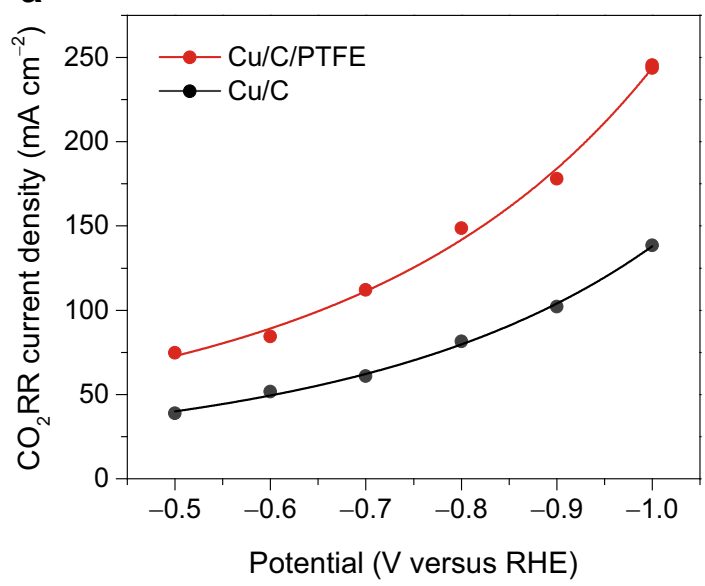

C
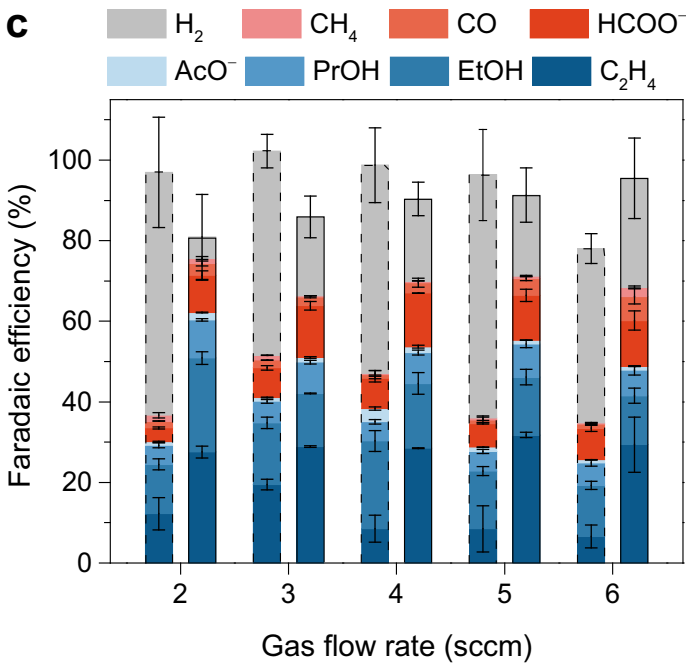

e

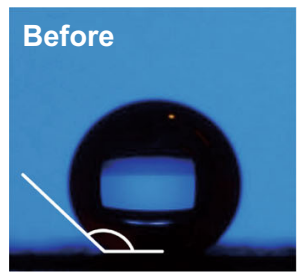

$144.2^{\circ}$

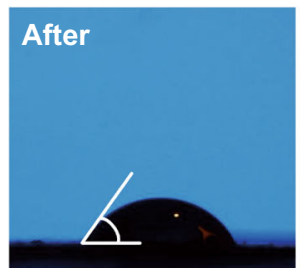

$55.4^{\circ}$

b

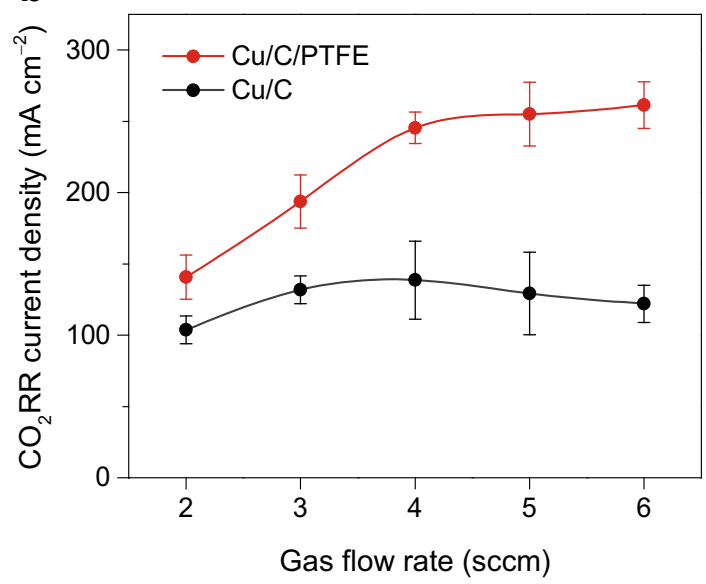

d

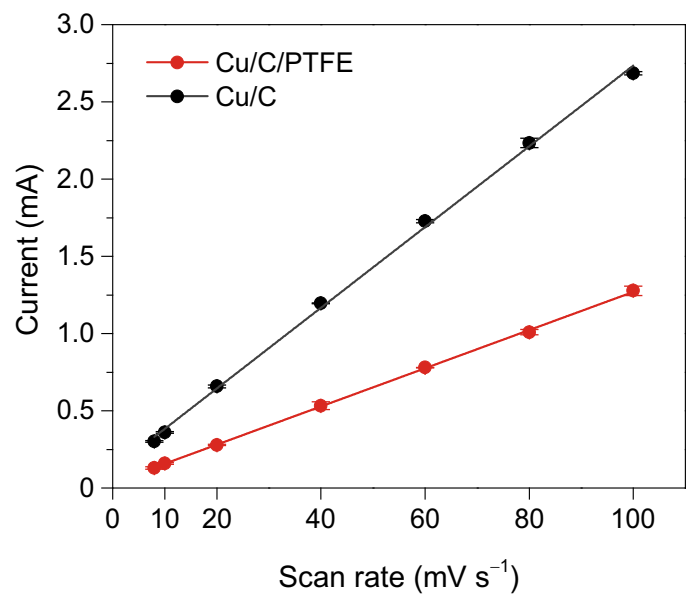

f

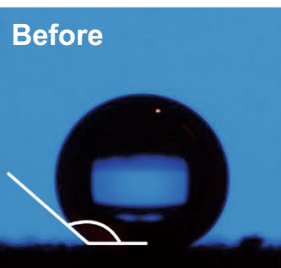

$150.8^{\circ}$

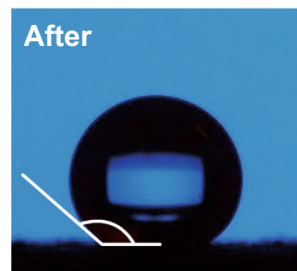

$144.7^{\circ}$

Fig. 3 Effect of hydrophobic microenvironment on the $\mathbf{C O}_{2} \mathbf{R R}$ in GDE cell. a Partial current densities for $\mathrm{CO}_{2} \mathrm{RR}$ on the $\mathrm{Cu} / \mathrm{C}$ and $\mathrm{Cu} / \mathrm{C} / \mathrm{PTFE}$ electrodes at various potentials with a $\mathrm{CO}_{2}$ gas flow rate of $4 \mathrm{sccm}$. $\mathbf{b}$ Partial current densities and $\mathbf{c}$ Faradaic efficiencies for $\mathrm{CO}_{2} \mathrm{RR}$ on the two electrodes at $-1.0 \mathrm{~V}$ with various $\mathrm{CO}_{2}$ flow rates. In c, the left column with dashed line frame at each flow rate is for the $\mathrm{Cu} / \mathrm{C}$ electrode and the right column with solid line frame is for the $\mathrm{Cu} / \mathrm{C} / \mathrm{PTFE}$ electrode. $\mathbf{d}$ Double-layer charging current plotted against the $\mathrm{CV}$ scan rate for the two electrodes. e, $\mathbf{f}$ Photographs of contact angle measurements on the $\mathbf{e} \mathrm{Cu} / \mathrm{C}$ electrode and $\mathbf{f} \mathrm{Cu} / \mathrm{C} / \mathrm{PTFE}$ electrode before and after $\mathrm{CO}_{2}$ electrolysis at $-1.0 \mathrm{~V}$ for $2 \mathrm{~h}$. The error bars represent the standard deviation of three independent measurements.

than the $\mathrm{Cu} / \mathrm{C}$ electrode at each potential. Particularly, a partial current density of $\sim 250 \mathrm{~mA} \mathrm{~cm}{ }^{-2}$ was reached for $\mathrm{CO}_{2} \mathrm{RR}$ on the $\mathrm{Cu} / \mathrm{C} / \mathrm{PTFE}$ electrode at $-1.0 \mathrm{~V}$, which was almost twice that of the $\mathrm{Cu} / \mathrm{C}$ electrode. We postulate that the dispersed PTFE nanoparticles in the catalyst layer form hydrophobic gas channels, which reduce the electrolyte layer thickness that $\mathrm{CO}_{2}$ must diffuse from the point of dissolution to the catalyst surface. This greatly decreases the diffusion layer thickness for the catalyst particles inside the catalyst layer, thus improving the $\mathrm{CO}_{2}$ mass transport and $\mathrm{CO}_{2} \mathrm{RR}$ performance.

To distinguish if the $\mathrm{CO}_{2}$ transport inside the catalyst layer was mainly mediated by gas-phase or aqueous-phase diffusion, we compared the $\mathrm{CO}_{2} \mathrm{RR}$ activity on the two electrodes with various $\mathrm{CO}_{2}$ gas flow rates. As presented in Fig. $3 \mathrm{~b}$, the $\mathrm{CO}_{2} \mathrm{RR}$ current density on the $\mathrm{Cu} / \mathrm{C}$ electrode at $-1.0 \mathrm{~V}$ showed a weak dependence on the flow rate, which increased from 104 to $138 \mathrm{~mA} \mathrm{~cm}^{-2}$ as the flow rate increased from 2 to $4 \mathrm{sccm}$, but declined to $122 \mathrm{~mA} \mathrm{~cm}^{-2}$ at a flow rate of $6 \mathrm{sccm}$. In contrast, the $\mathrm{CO}_{2} \mathrm{RR}$ current density on the $\mathrm{Cu} / \mathrm{C} / \mathrm{PTFE}$ electrode showed a distinct trend, which increased almost linearly from 140 to $250 \mathrm{~mA} \mathrm{~cm}^{-2}$ as the flow rate increased from 2 to $4 \mathrm{sccm}$ and then continued to increase mildly at higher flow rates. As a result, a maximum single-pass conversion rate of $14 \%$ was reached for $\mathrm{CO}_{2} \mathrm{RR}$ on the $\mathrm{Cu} / \mathrm{C} / \mathrm{PTFE}$ electrode at $4 \mathrm{sccm}$, which is about 
twice that of the $\mathrm{Cu} / \mathrm{C}$ electrode $(7.3 \%)$ at the same flow rate (Supplementary Fig. 14). As previously discussed, if the $\mathrm{CO}_{2} \mathrm{RR}$ is only mediated by aqueous-phase transport of dissolved $\mathrm{CO}_{2}$ molecules to the catalyst, the reaction rate should not be affected by the $\mathrm{CO}_{2}$ gas flow rate (Fig. 2c). Here, the strong dependence of the $\mathrm{CO}_{2} \mathrm{RR}$ current density on the flow rate for the $\mathrm{Cu} / \mathrm{C} / \mathrm{PTFE}$ electrode indicated a gas-phase transport of $\mathrm{CO}_{2}$ in the catalyst layer via hydrophobic channels. In addition, the $\mathrm{CO}_{2} \mathrm{RR}$ selectivity was different between the two electrodes, as presented in Fig. 3c. The total Faradaic efficiency for $\mathrm{CO}_{2} \mathrm{RR}$ on the $\mathrm{Cu} / \mathrm{C}$ electrode ranged between 35 and $50 \%$ at various flow rates, while the total Faradaic efficiency on the $\mathrm{Cu} / \mathrm{C} / \mathrm{PTFE}$ electrode was higher, ranging between 68 and $76 \%$. The Faradic efficiency for $\mathrm{C}_{2+}$ products was also higher on the $\mathrm{Cu} / \mathrm{C} / \mathrm{PTFE}$ electrode, suggesting that the electrode increased the local concentration of the intermediate product $\mathrm{CO}$ and consequently enhanced the C-C coupling process ${ }^{16,45}$.

It is noted that the added PTFE will increase the catalyst layer thickness of the $\mathrm{Cu} / \mathrm{C} / \mathrm{PTFE}$ electrode, which can influence the diffusion of $\mathrm{CO}_{2}$ and $\mathrm{CO}_{2} \mathrm{RR}$ activity. As revealed by the SEM images in Supplementary Fig. 15, the catalyst layer thickness was estimated to be $23.5 \pm 2.1$ and $39.3 \pm 2.6 \mu \mathrm{m}$ for the $\mathrm{Cu} / \mathrm{C}$ and $\mathrm{Cu} /$ $\mathrm{C} / \mathrm{PTFE}$ electrodes, respectively. To evaluate the influence of the catalyst layer thickness, an additional $\mathrm{Cu} / \mathrm{C}$ electrode with extra carbon black loading was prepared (referred as $\mathrm{Cu} / \mathrm{C}$-extra electrode), of which the catalyst layer thickness $(40.6 \pm 1.8 \mu \mathrm{m})$ is close to that of the $\mathrm{Cu} / \mathrm{C} / \mathrm{PTFE}$ electrode. A comparison of their $\mathrm{CO}_{2} \mathrm{RR}$ performance was shown in Supplementary Fig. 15d: the partial current density and total Faradaic efficiency for $\mathrm{CO}_{2} \mathrm{RR}$ on the $\mathrm{Cu} / \mathrm{C}$-extra electrode was similar to that of the $\mathrm{Cu} / \mathrm{C}$ electrode, but the Faradaic efficiency for $\mathrm{C}_{2+}$ products was lower on the $\mathrm{Cu} / \mathrm{C}$-extra electrode, which was attributed to the relatively lower concentration of $\mathrm{CO}_{2}$ inside the catalyst layer ${ }^{16}$. This is reasonable as $\mathrm{CO}_{2}$ needs to diffuse over a longer distance on average to reach the catalyst particles in a thicker catalyst layer. Interestingly, the $\mathrm{Cu} / \mathrm{C} / \mathrm{PTFE}$ electrode had a similarly thicker catalyst layer, but its $\mathrm{CO}_{2} \mathrm{RR}$ current density and $\mathrm{C}_{2+}$ Faradaic efficiency were both much higher than that of the $\mathrm{Cu} / \mathrm{C}$ and $\mathrm{Cu} /$ $\mathrm{C}$-extra electrodes, confirming the improvement of $\mathrm{CO}_{2}$ mass transport and $\mathrm{CO}_{2} \mathrm{RR}$ performance by the hydrophobic microenvironment, despite a thicker catalyst layer.

To further verify the presence of gaseous reactant inside the catalyst layer, we compared the electrochemically active surface area (ECSA) of the two electrodes. ECSA represents the area of an electrode that is wetted and accessible to the electrolyte. We postulate that the increased volume of gas within the catalyst layer will reduce its ECSA due to less contact with the electrolyte. The ECSA is proportional to the electrochemical double-layer capacitance, which can be measured by cyclic voltammetry $(\mathrm{CV})$ in a potential window where only double-layer charging and discharging occur ${ }^{46}$, as illustrated in Supplementary Fig. 16. The double-layer charging current was plotted against the scan rate, and the slope of the linear regression gives the double-layer capacitance. As shown in Fig. 3d, the capacitance of the $\mathrm{Cu} / \mathrm{C} /$ PTFE electrode $(\sim 12.4 \mathrm{mF})$ was around half that of the $\mathrm{Cu} / \mathrm{C}$ electrode $(\sim 26.1 \mathrm{mF})$, despite the same loading of $\mathrm{Cu}$ and carbon black. This confirmed the presence of gas bubbles in the catalyst layer and the formation of solid-liquid-gas interfaces.

A balance between gas and liquid in a GDE may be broken during electrolysis, as the electrode often becomes hydrophilic due to electrochemical modifications so that the pores in the catalyst layer are flooded by the electrolyte ${ }^{30,31}$, which will suppress the mass transport and lead to a decline of the reaction rate. For example, as shown in Fig. 3e, the catalyst side of the $\mathrm{Cu} /$ C electrode exhibited a contact angle of $144.2^{\circ}$ initially, which however dropped significantly to $55.4^{\circ}$ after $\mathrm{CO}_{2} \mathrm{RR}$ at $-1.0 \mathrm{~V}$ for
$2 \mathrm{~h}$, indicating an evolution of the electrode's hydrophobicity and flooding of the electrode ${ }^{31}$. In contrast, the $\mathrm{Cu} / \mathrm{C} / \mathrm{PTFE}$ electrode exhibited a contact angle of $150.8^{\circ}$ and $144.7^{\circ}$ before and after electrolysis (Fig. 3f), suggesting that the added PTFE particles preserved the hydrophobicity and prevented the catalyst layer from flooding, so that a balanced gas/liquid microenvironment was maintained in the catalyst layer to form durable solid-liquid-gas interfaces for $\mathrm{CO}_{2}$ electrolysis.

Effects of PTFE loading and size on the microenvironment. The gas/liquid microenvironment inside the catalyst layer depends on the added PTFE particles, particularly their loading and size. To elucidate their effects, we first varied the loading of the PTFE nanoparticles with otherwise the same amount of $\mathrm{Cu}$ nanoparticles and carbon black. Figure 4a shows the partial current densities for $\mathrm{CO}_{2} \mathrm{RR}$ on the $\mathrm{Cu} / \mathrm{C} / \mathrm{PTFE}$ electrodes with different PTFE mass ratios in the catalyst layer. As the mass ratio increased from 0 , the $\mathrm{CO}_{2} \mathrm{RR}$ activity increased until a maximum value was reached at a 50\% mass ratio of PTFE, while an even higher ratio caused a decline of the activity. The total Faradaic efficiency for $\mathrm{CO}_{2} \mathrm{RR}$ exhibited a similar dependence on the PTFE mass ratio from 0 to $50 \%$, but it did not drop at a higher ratio of $70 \%$ (Fig. $4 \mathrm{~b}$ ). Thus, a moderate amount of PTFE can create a hydrophobic microenvironment to enhance the $\mathrm{CO}_{2} \mathrm{RR}$ activity and Faradaic efficiency, but excessive PTFE will over suppress the availability of electrolyte and protons for $\mathrm{CO}_{2} \mathrm{RR}$. An optimal balance between gas and liquid in the catalyst layer is needed for efficient $\mathrm{CO}_{2}$ electrolysis. To directly build a relationship between the electrode hydrophobicity and $\mathrm{CO}_{2} \mathrm{RR}$ performance, we measured the contact angles of these electrodes and plotted the $\mathrm{CO}_{2} \mathrm{RR}$ current density versus the contact angles, as shown in Supplementary Fig. 17. The contact angles before $\mathrm{CO}_{2} \mathrm{RR}$ were close, ranging from $144.2^{\circ}$ (0\% PTFE) to $155.1^{\circ}$ (70\% PTFE), but the contact angles after $\mathrm{CO}_{2} \mathrm{RR}$ decreased to various degrees: the more the PTFE loading was, the larger the contact angle remained. Therefore, only the contact angle measured after electrolysis reflects an electrode's capability of repelling liquid and stabilizing gas/liquid microenvironment in the catalyst layer for $\mathrm{CO}_{2} \mathrm{RR}$.

The gas-liquid balance in the catalyst layer also depends on the size of hydrophobic pores, which is correlated with the PTFE particle size. The capillary pressure difference sustained across the interface between liquid and gas is determined by the Young-Laplace equation: $P_{\text {liquid }}-P_{\text {gas }}=2 \sigma / R$, where $\sigma$ is the surface tension of $1 \mathrm{M} \mathrm{KOH}$ electrolyte $\left(74.4 \mathrm{mN} \mathrm{m}^{-1}\right)^{47}$, and $R$ is the radius of curvature of the interface. In addition, as illustrated in Fig. $4 \mathrm{c}, R=r / \sin \left(\theta_{\mathrm{a}}-90^{\circ}\right)$, where $r$ is the pore radius and $\theta_{\mathrm{a}}$ is the advancing contact angle of the electrolyte on the electrode $\left(\sim 150.8^{\circ}\right)$. Based on the equation, a smaller pore requires a higher critical burst-through pressure for liquid to enter the pore ${ }^{33}$, as plotted in Fig. $4 \mathrm{c}$. Thus, the catalyst layer with smaller PTFE particles should form smaller hydrophobic pores that are more effective in repelling liquid and maintaining gas in the pores.

To verify the effect of PTFE particle size, two Cu/C/PTFE electrodes were prepared with different PTFE particles: one is of $30-40 \mathrm{~nm}$ in size (Nanoshel LLC), and the other is of $\sim 1 \mu \mathrm{m}$ in size (Sigma Aldrich), both with a 50\% mass ratio in the catalyst layer. They are referred as $\mathrm{Cu} / \mathrm{C} / \mathrm{PTFE}(\mathrm{S})$ and $\mathrm{Cu} / \mathrm{C} / \mathrm{PTFE}(\mathrm{L})$, respectively. The two electrodes were evaluated for $\mathrm{CO}_{2} \mathrm{RR}$ in the GDE cell with various $\mathrm{CO}_{2}$ flow rates. As shown in Fig. $4 \mathrm{~d}$, the $\mathrm{CO}_{2} \mathrm{RR}$ current density on the $\mathrm{Cu} / \mathrm{C} / \mathrm{PTFE}(\mathrm{L})$ electrode similarly increased with the flow rate, but it was generally lower than that on the $\mathrm{Cu} / \mathrm{C} /$ PTFE(S) electrode due to the larger hydrophobic pores with a weaker repelling of liquid electrolyte. Similar difference was 

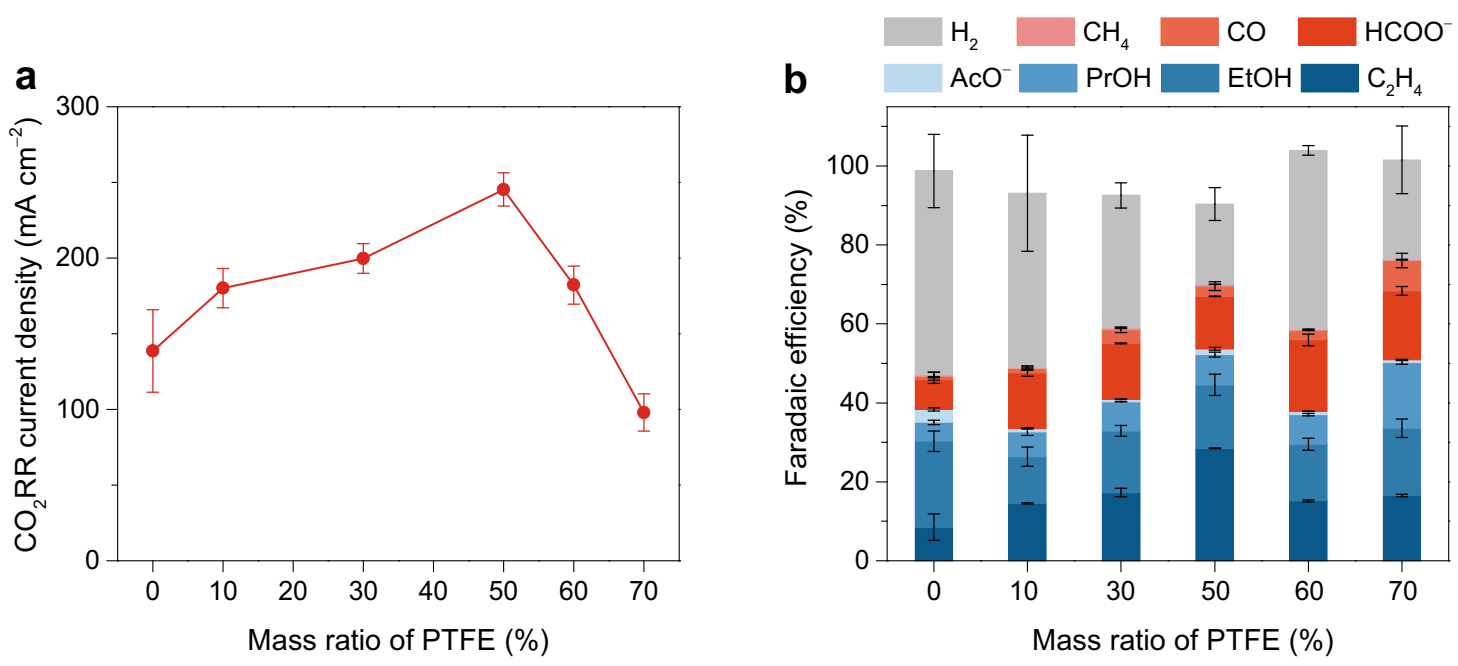

C

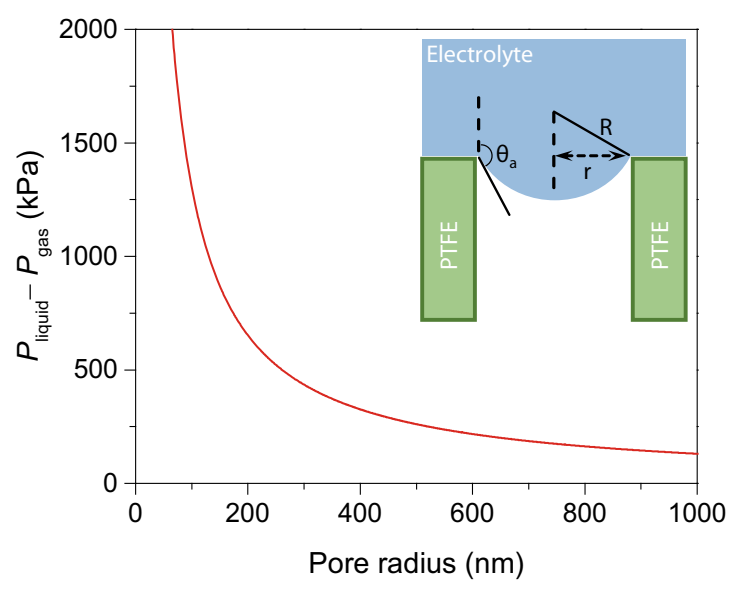

d
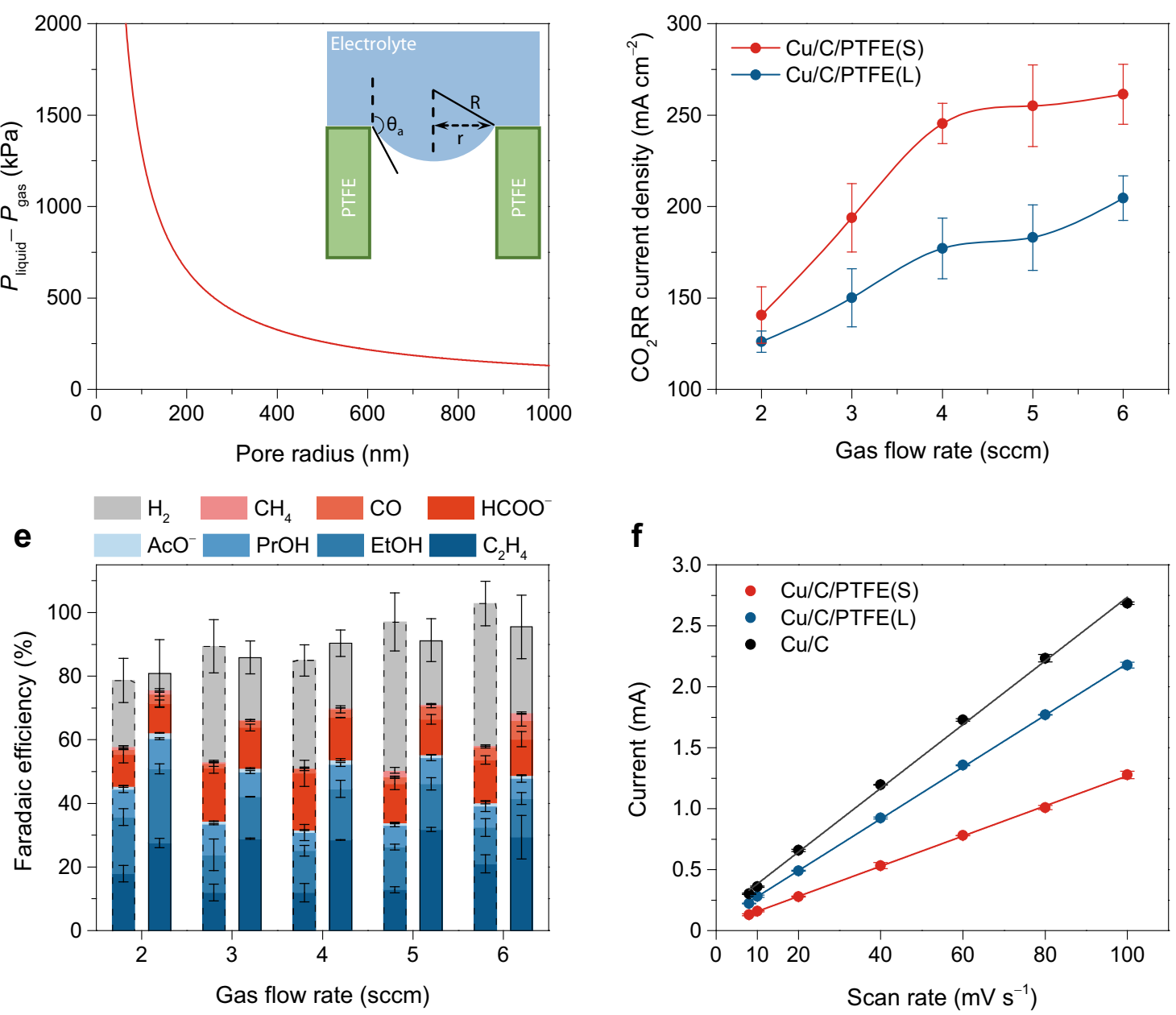

Fig. 4 Effects of PTFE loading and size on the microenvironment for $\mathbf{C O}_{\mathbf{2}} \mathbf{R R}$ in GDE cell. a Partial current densities and $\mathbf{b}$ Faradaic efficiencies for $\mathrm{CO}_{2} \mathrm{RR}$ at $-1.0 \mathrm{~V}$ on $\mathrm{Cu} / \mathrm{C} / \mathrm{PTFE}$ electrodes with different mass ratios of PTFE in the catalyst layer. c Pressure difference sustained across the liquid-gas interface in nano-sized pores as a function of the pore radius. Inset: schematic of the interface advancing inside a pore. $\mathbf{d}$ Partial current densities and $\mathbf{e}$ Faradaic efficiencies for $\mathrm{CO}_{2} \mathrm{RR}$ on two $\mathrm{Cu} / \mathrm{C} / \mathrm{PTFE}$ electrodes with different PTFE particle sizes. In e, the left column with dashed line frame at each flow rate is for the $\mathrm{Cu} / \mathrm{C} / \mathrm{PTFE}(\mathrm{L})$ electrode and the right column with solid line frame is for the $\mathrm{Cu} / \mathrm{C} / \mathrm{PTFE}(\mathrm{S})$ electrode. $\mathbf{f}$ Double-layer charging current plotted against the CV scan rate for the electrodes. The error bars represent the standard deviation of three independent measurements. 
a

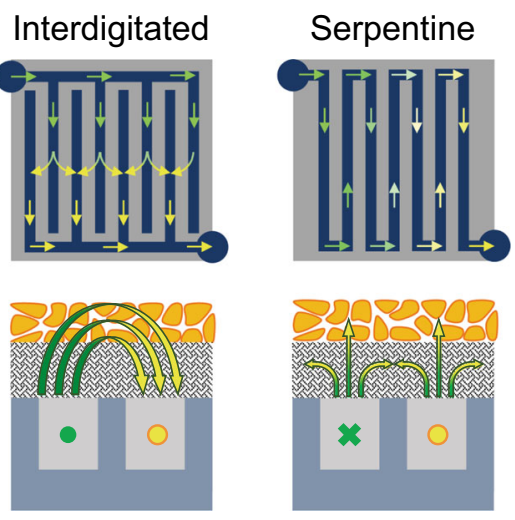

b

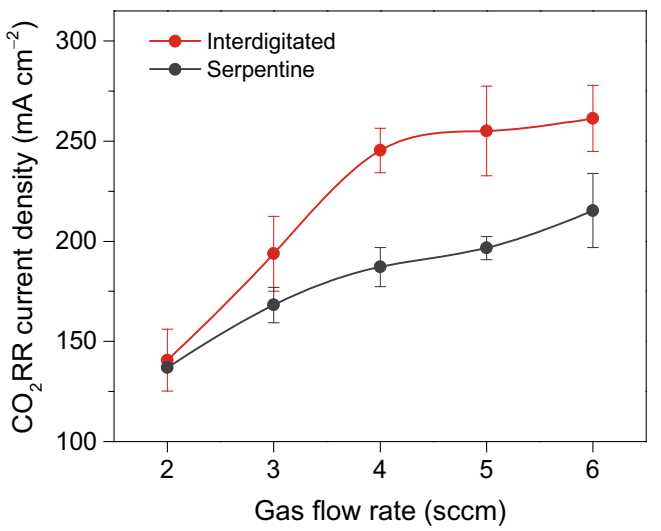

Fig. 5 Effect of gas-diffusion channels on the $\mathbf{C O}_{\mathbf{2}} \mathbf{R} \mathbf{R}$ in $\mathbf{G D E}$ cell. a Schematic illustration of the gas flow fields generated by the interdigitated and serpentine channels. b Partial current densities for $\mathrm{CO}_{2} \mathrm{RR}$ on the $\mathrm{Cu} / \mathrm{C} / \mathrm{PTFE}$ electrode (with a 50\% PTFE mass ratio) with two different channels at $-1.0 \mathrm{~V}$ with various $\mathrm{CO}_{2}$ gas flow rates. The error bars represent the standard deviation of three independent measurements.

observed in the total Faradaic efficiency for $\mathrm{CO}_{2} \mathrm{RR}$ on the two electrodes, as well as the Faradic efficiency for $\mathrm{C}_{2+}$ products, as shown in Fig. 4e. The effect of PTFE particle size on the formed microenvironment can be further examined by double-layer capacitance that reflects the area wetted by the electrolyte. The linear fit in Fig. $4 \mathrm{f}$ revealed a capacitance of $21.2 \mathrm{mF}$ of the $\mathrm{Cu} / \mathrm{C} /$ PTFE(L) electrode, which is larger than that of the $\mathrm{Cu} / \mathrm{C} / \mathrm{PTFE}(\mathrm{S})$ electrode $(\sim 12.4 \mathrm{mF})$, but still smaller than that of the $\mathrm{Cu} / \mathrm{C}$ electrode $(\sim 26.1 \mathrm{mF})$, validating the effect of PTFE particle size in creating a gas/liquid microenvironment inside the catalyst layer.

Effect of gas-diffusion channels. As the $\mathrm{CO}_{2} \mathrm{RR}$ activity of the $\mathrm{Cu} / \mathrm{C} / \mathrm{PTFE}$ electrode depends on the $\mathrm{CO}_{2}$ gas flow rate, the gas flow field in the GDE can be engineered to enhance the $\mathrm{CO}_{2}$ transport via the design of gas-diffusion channels, such as interdigitated and serpentine channels (Fig. 5a). Recent studies of $\mathrm{CO}_{2} \mathrm{RR}$ in GDE cells often used serpentine channels ${ }^{21,24}$, where the neighboring channels are connected so that gas diffuses along the channels from inlet to outlet. In this design, the vertical diffusion of gas into the electrode and catalyst layer is driven by pressure gradient. In contrast, in the interdigitated design the inlet and outlet rows are aligned alternately and separately by walls, so the inlet gas is forced to diffuse vertically into the electrode and then exit to the outlet channels ${ }^{48}$. Such a flow field is more effective in driving the mass transport of $\mathrm{CO}_{2}$ into the catalyst layer. Thus, we compared $\mathrm{CO}_{2} \mathrm{RR}$ on the $\mathrm{Cu} / \mathrm{C} / \mathrm{PTFE}$ electrode in GDE cells with interdigitated and serpentine flow fields. As shown in Fig. 5b, the $\mathrm{CO}_{2} \mathrm{RR}$ current density increased with the gas flow rate for both designs, but the one with interdigitated channels showed a higher $\mathrm{CO}_{2} \mathrm{RR}$ current density, as well as a sharper increase with the flow rate, indicating a more efficient transport of gaseous $\mathrm{CO}_{2}$ to the catalyst with the interdigitated flow field.

\section{Discussion}

The above results confirmed the formation of a balanced gas/ liquid microenvironment inside the catalyst layer of the $\mathrm{Cu} / \mathrm{C} /$ PTFE electrode for $\mathrm{CO}_{2}$ electrolysis. Compared to regular GDEs, the added PTFE particles create hydrophobic pores for gas-phase $\mathrm{CO}_{2}$ transport inside the catalyst layer, which greatly reduces the diffusion layer thickness as compared to a regular catalyst layer that is wetted by electrolyte ${ }^{29}$. To quantify the effect, we obtained the EIS of the electrodes under $\mathrm{CO}_{2} \mathrm{RR}$ conditions and model them to estimate the diffusion layer thickness. EIS is an effective and noninvasive method to investigate Nernst diffusion process in a multilayer system ${ }^{49}$, which can be described by an equivalent impedance $Z_{\mathrm{d}}$ in circuit modeling. Supplementary Fig. 18 shows the circuit model and its equivalent ladder circuit to describe the impedances in a porous carbon electrode ${ }^{50}$, as well as the EIS measured for the $\mathrm{Cu} / \mathrm{C}, \mathrm{Cu} / \mathrm{C} / \mathrm{PTFE}(\mathrm{S})$, and $\mathrm{Cu} / \mathrm{C} / \mathrm{PTFE}(\mathrm{L})$ electrodes under $\mathrm{CO}_{2} \mathrm{RR}$ conditions in the GDE cell. The feature in the low frequency region of the EIS is attributed to the impedance of the diffusion layer ${ }^{49}$. The finite diffusion layer thickness $\delta$ in our system can be theoretically derived from $Z_{\mathrm{d}}$ (ref. ${ }^{51}$ ), and the diffusion layer thickness was estimated to be $20.2 \pm 3.1,3.2 \pm 0.9$, and $7.3 \pm 0.8 \mu \mathrm{m}$ for the $\mathrm{Cu} / \mathrm{C}, \mathrm{Cu} / \mathrm{C} / \mathrm{PTFE}$ $(\mathrm{S})$, and $\mathrm{Cu} / \mathrm{C} / \mathrm{PTFE}(\mathrm{L})$ electrodes, respectively. The data further quantitatively confirmed our conclusion: the diffusion layer thickness greatly reduced from 20.2 to $3.2 \mu \mathrm{m}$ after dispersing PTFE particles in the catalyst layer, because the PTFE can enable gas-phase transport of $\mathrm{CO}_{2}$ in the catalyst layer and reduce the thickness of liquid electrolyte that $\mathrm{CO}_{2}$ must diffuse through to reach the catalyst. The estimated diffusion layer thickness for the $\mathrm{Cu} / \mathrm{C} / \mathrm{PTFE}(\mathrm{L})$ electrode is also consistent with our expectation and the measured $\mathrm{CO}_{2} \mathrm{RR}$ performance.

The reduced diffusion layer thickness accelerates the transport of $\mathrm{CO}_{2}$ to the catalyst, resulting in an increased steady concentration of $\mathrm{CO}_{2}$ near the catalyst ${ }^{29}$, as shown in Supplementary Fig. 19. At equilibrium, the surface coverage of ${ }^{*} \mathrm{CO}_{2}\left(\theta_{\mathrm{CO}_{2}}\right)$ adsorbed on the catalyst is proportional to the local concentration of $\mathrm{CO}_{2}$ as follows ${ }^{16}: \theta_{\mathrm{CO}_{2}}=\theta^{*} \cdot\left[\mathrm{CO}_{2}\right] \cdot \exp \left(-E_{\mathrm{CO}_{2}} / R T\right)$, where $\theta^{*}$ is the coverage of available surface sites, $\left[\mathrm{CO}_{2}\right]$ is the $\mathrm{CO}_{2}$ local concentration, $E_{\mathrm{CO}_{2}}$ is the adsorption energy of $\mathrm{CO}_{2}$ on the catalyst, $R$ is the ideal gas constant, and $T$ is the temperature. Therefore, we propose that the hydrophobic microenvironment in the $\mathrm{Cu} / \mathrm{C} / \mathrm{PTFE}$ electrode enhances the mass transport and adsorption of $\mathrm{CO}_{2}$, resulting in an increased coverage of ${ }^{*} \mathrm{CO}_{2}$ on the catalyst surface for reactions ${ }^{18,32}$. This will increase the $\mathrm{CO}_{2} \mathrm{RR}$ rate, as well as the produced $\mathrm{CO}$ for $\mathrm{C}-\mathrm{C}$ coupling, thus improving the Faradaic efficiency for $\mathrm{C}_{2+}$ products. The hydrophobic microenvironment may also trap the produced CO inside the catalyst layer, which can increase the local concentration of $\mathrm{CO}$ to enhance $\mathrm{C}-\mathrm{C}$ coupling toward $\mathrm{C}_{2+}$ products ${ }^{16,45}$.

Furthermore, the ECSA of the Cu/C/PTFE electrode is around half that of the $\mathrm{Cu} / \mathrm{C}$ electrode (Fig. 3d), so half of the $\mathrm{Cu}$ nanoparticles are not in contact with the electrolyte and the surfaces of these catalyst particles are inactive for $\mathrm{CO}_{2} \mathrm{RR}$ due to the lack of protons and ionic conductivity. On the other hand, some catalyst particles may be located at the boundary between gas and liquid, so they are accessible to both gaseous $\mathrm{CO}_{2}$ 
molecules and liquid electrolyte. Thus, $\mathrm{CO}_{2}$ molecules from the gas side, and protons or water molecules from the liquid side can promote $\mathrm{CO}_{2} \mathrm{RR}$ at the three-phase boundary sites of the catalyst surface, as schematically shown in Supplementary Fig. 20. Such three-phase boundary sites can be highly active for $\mathrm{CO}_{2} \mathrm{RR}$ due to the direct and fast gas-phase adsorption of $\mathrm{CO}_{2}$ on the catalyst surface without the influence of electric double layer and solvated ions ${ }^{52-54}$. This can explain the dependence of the $\mathrm{CO}_{2} \mathrm{RR}$ activity on the gas flow rate for the $\mathrm{Cu} / \mathrm{C} / \mathrm{PTFE}$ electrode due to the gasphase transport and adsorption of $\mathrm{CO}_{2}$.

As a proof-of-concept study, we used commercial $\mathrm{Cu}$ nanoparticles for simplicity, which are intrinsically less active than those optimized $\mathrm{Cu}$ catalysts ${ }^{19-22}$. As a result, the $\mathrm{CO}_{2} \mathrm{RR}$ performance here may not be as high as that in some reports, but the significance of our study lies in the new understanding and a general approach to control the catalyst microenvironment for gas-involving electrochemical reactions. Our work differs from some prior studies that tuned the composition of the MPL ${ }^{20}$ or added PTFE suspensions in the catalyst layer ${ }^{55}$, where the PTFE particles were coated by surfactant that could weaken the hydrophobicity. In addition, some studies used $\mathrm{CO}_{2}$ flow rates as high as 50 or $100 \mathrm{sccm}^{21,24}$, which may create a high local pressure in the gas side of the $\mathrm{GDE}^{56}$ and enhance the $\mathrm{CO}_{2}$ mass transport to improve $\mathrm{CO}_{2} \mathrm{RR}$ performance ${ }^{57}$. Our study achieved a high activity and selectivity for $\mathrm{CO}_{2} \mathrm{RR}$ with a much lower $\mathrm{CO}_{2}$ flow rate $(4 \mathrm{sccm})$, resulting in a high single-pass conversion rate of $\mathrm{CO}_{2}$ of $\sim 14 \%$ (Supplementary Fig. 14), benefiting from the catalyst microenvironment. Our method of controlling local gas/ liquid microenvironment can be generally applied to improve other gas-involving electrocatalysis, when gaseous reactant has a low solubility and slow diffusion in the electrolyte, such as the electrochemical reduction of $\mathrm{N}_{2}$ (ref. ${ }^{58}$ ).

In summary, we developed a GDE with a hydrophobic microenvironment for $\mathrm{CO}_{2}$ electrolysis by dispersing PTFE nanoparticles in the catalyst layer, where the PTFE can repel liquid electrolyte and maintain gaseous reactant near the catalyst particles. The $\mathrm{Cu} / \mathrm{C} /$ PTFE electrode showed a significant improvement in the activity, Faradaic efficiency, and $\mathrm{C}_{2+}$ product selectivity for $\mathrm{CO}_{2} \mathrm{RR}$ as compared to a regular $\mathrm{Cu} / \mathrm{C}$ electrode without added PTFE. Furthermore, the $\mathrm{CO}_{2} \mathrm{RR}$ current density on the $\mathrm{Cu} / \mathrm{C} / \mathrm{PTFE}$ electrode increased with the $\mathrm{CO}_{2}$ gas flow rate, indicating a gas-phase transport of $\mathrm{CO}_{2}$ in the catalyst layer. The improved performance is attributed to the reduced diffusion layer thickness that accelerates $\mathrm{CO}_{2}$ mass transport, increases the local concentration of $\mathrm{CO}_{2}$ near the catalyst surface, and enhances $\mathrm{CO}_{2}$ adsorption for the reaction. Compared to regular GDEs, the electrode with added PTFE particles creates a balanced gas/liquid microenvironment and solidliquid-gas interfaces inside the catalyst layer, which can enhance the mass transport and kinetics of $\mathrm{CO}_{2}$ electrolysis, providing a general approach to improve gas-involving electrocatalysis.

\begin{abstract}
Methods
Materials characterization. TEM images were acquired using a FEI Tecnai F30 transmission electron microscope with a field emission gun operated at $200 \mathrm{kV}$. SEM images and EDS elemental mapping were acquired using a ZEISS Ultra-55 FEG scanning electron microscope. XRD pattern was collected using a PANalytical Empyrean diffractometer with a $1.8 \mathrm{KW}$ copper X-ray tube. XPS data were acquired by a Thermo Scientific ESCALAB XI ${ }^{+} \mathrm{X}$-ray Photoelectron Spectrometer with an $\mathrm{Al} \mathrm{Ka} \mathrm{X-ray} \mathrm{source}(1486.67 \mathrm{eV})$. Operando XAS was performed at Beamline 2-2 of the Stanford Synchrotron Radiation Lightsource at the SLAC National Accelerator Laboratory using a modified two-compartment $\mathrm{H}$-cell and a Lytle fluorescence detector (Supplementary Fig. 3). The XAS data were processed using the ATHENA software ${ }^{59}$. Contact angle measurements were carried out using an L2004A1 Ossila Contact Angle Goniometer (Ossila Ltd, UK).
\end{abstract}

Preparation of electrodes for $\mathrm{CO}_{2} \mathbf{R R}$ in H-cell. First, $6 \mathrm{mg}$ of commercial $\mathrm{Cu}$ nanoparticles (US1828, US Research Nanomaterials) and $6 \mathrm{mg}$ of Vulcan XC 72 carbon black (Fuel Cell Store) were each dispersed in $2 \mathrm{~mL}$ isopropanol, respectively. After sonication for $1 \mathrm{~h}$, the two dispersions were mixed with $200 \mu \mathrm{L}$ Nafion solution (5 wt\%) and sonicated for another $1 \mathrm{~h}$. The mixture was used as the catalyst ink and sprayed on electrode substrates by a homemade XY plotter equipped with an airbrush. Two types of substrates with an area of $1 \times 1 \mathrm{~cm}^{2}$ were used: AvCarb MGL370 and AvCarb GDS2230 (Fuel Cell Store). After deposition, the electrodes were dried overnight at room temperature, with a $\mathrm{Cu}$ catalyst loading of $0.65 \pm 0.05 \mathrm{mg} \mathrm{cm}^{-2}$.

Preparation of electrodes for $\mathbf{C O}_{\mathbf{2}} \mathbf{R R}$ in GDE cell. The same catalyst ink in the $\mathrm{H}$-cell studies was used as 0\% PTFE-catalyst ink here. The PTFE-dispersed catalyst layer was prepared as follows. First, $6 \mathrm{mg}$ of commercial Cu nanoparticles (US1828, US Research Nanomaterials) and $6 \mathrm{mg}$ of Vulcan XC 72 carbon black (Fuel Cell Store) were each dispersed in $1 \mathrm{~mL}$ isopropanol, respectively. Then, 2.2, 8.7, 20, 30, and $46.7 \mathrm{mg}$ PTFE nanopowder (APS 30-40 nm, Nanoshel LLC) were dispersed in $2 \mathrm{~mL}$ isopropanol, respectively. After sonication for $1 \mathrm{~h}$, Cu nanoparticle dispersion, carbon black dispersion, corresponding PTFE dispersion, and $200 \mu \mathrm{L}$ Nafion solution ( $5 \mathrm{wt} \%$, containing $\sim 8 \mathrm{mg}$ Nafion) were mixed and sonicated for another $1 \mathrm{~h}$, which were used as $10 \%, 30 \%, 50 \%, 60 \%$, and $70 \%$ PTFE-catalyst inks, respectively. Each catalyst ink was sprayed on an AvCarb GDS2230 substrate with a $\mathrm{Cu}$ catalyst loading of $0.65 \pm 0.05 \mathrm{mg} \mathrm{cm}^{-2}$. After drying overnight, $1 \mathrm{~mL}$ of diluted Teflon PTFE DISP 30 solution (0.12 wt\%, Fuel Cell Store) was further sprayed on top of all electrodes except the $0 \%$ PTFE one. All the samples were dried in air for at least $5 \mathrm{~h}$ before testing.

Electrochemical measurements. Electrochemical tests were performed using a Gamry Interface 1000 Potentiostat or a CH Instruments 760E Potentiostat with an $\mathrm{H}$-cell or a home-built GDE flow cell. The H-cell experiments were carried out in a gas-tight two-compartment $\mathrm{H}$-cell separated by a Nafion 1110 membrane under ambient conditions (Supplementary Fig. 6). A platinum gauze and an $\mathrm{Ag} / \mathrm{AgCl}$ electrode with saturated $\mathrm{KCl}$ solution (BASi MF-2056) were used as the counter electrode and the reference electrode, respectively. Electrodes prepared with AvCarb MGL370 or GDS2230 substrate were used as the working electrode. $\mathrm{CO}_{2-}$ saturated $1 \mathrm{M} \mathrm{KHCO}_{3}$ solution was used as the electrolyte, which was stirred at a rate of 600 r.p.m. during electrolysis. GDE-cell studies were performed using a home-built GDE flow cell (Supplementary Fig. 12), including a Ti current collector with interdigitated gas-diffusion channels, a cathodic GDE with catalyst layer on AvCarb GDS2230 substrate, a 3D-printed chamber with ports for electrolyte flow and reference electrode, and an $\mathrm{Fe}-\mathrm{Ni}$ foam inserted in a pocket of $\mathrm{Ti}$ current collector as the anode ${ }^{28}$. The gas-diffusion channels have a depth of $0.2 \mathrm{~mm}$ and a density of 50 channels $\mathrm{cm}^{-1}$. A Nafion 1110 or FAA-3-PK-130 membrane was used to separate the cathode and anode chambers. A leak-free $\mathrm{Ag} / \mathrm{AgCl}$ electrode (Warner Instruments) was used as the reference electrode. The above prepared electrodes were used as working electrodes with an effective area of $0.66 \mathrm{~cm}^{2}$. The catholyte and the anolyte were each $20 \mathrm{~mL}$ of $1 \mathrm{M} \mathrm{KOH}$ solution circulated using peristaltic pumps at a flow rate ranging from $0.6-2.2 \mathrm{~mL} \mathrm{~min}^{-1}$. For both $\mathrm{H}$-cell and GDE-cell studies, $\mathrm{CO}_{2}$ gas flow was controlled by an Alicat mass flow controller at a specified flow rate ranging from $2-6 \mathrm{sccm}$, and the applied potentials were iR-compensated and converted to the RHE scale. The reported partial current densities for $\mathrm{CO}_{2} \mathrm{RR}$ were normalized to geometric surface areas. The EIS data were fit with a circuit model ${ }^{50}$ using the EIS Spectrum Analyser ${ }^{60}$

During electrolysis, gas-phase products from the H-cell or GDE cell were quantified by a gas chromatograph (SRI Multiple Gas Analyzer \#5) equipped with molecular sieve 5A and HayeSep D columns with $\mathrm{Ar}$ as the carrier gas. Solutionphase products were analyzed using a Bruker AVIII $500 \mathrm{MHz}$ NMR spectrometer. Typically, $500 \mu \mathrm{L}$ of the post-electrolysis catholyte was mixed with $100 \mu \mathrm{L}$ of $\mathrm{D}_{2} \mathrm{O}$ containing 100 p.p.m. dimethyl sulfoxide as the internal standard. ${ }^{1} \mathrm{H}$ NMR spectra were acquired using water suppression mode.

Electrochemically active surface area measurement. The ECSA of an electrode was quantified by measuring the double-layer capacitance. CV was performed in the GDE flow cell at different scan rates in a potential window where only doublelayer charging and discharging occur (no Faradaic process). The double-layer charging current was then plotted versus the CV scan rate, and the slope of the linear regression gave the double-layer capacitance. A representative set of the $\mathrm{CV}$ scans is exhibited in Supplementary Fig. 16.

Calculation of $\mathrm{CO}_{2} \mathrm{RR}$ current density and Faradaic efficiency. The gas-phase products were quantified by comparison of the peak integrals to standard calibration gases to determine the molar flow rate of a product $(V)$. The Faradaic efficiency (FE) for each gas-phase product was calculated using the following equation:

$$
\mathrm{FE}=\frac{n F V}{I_{\text {total }}} \times 100 \%,
$$

where $n$ is the number of electrons transferred for the product, $F$ is the Faraday constant, $V$ is the molar flow rate of the product, and $I_{\text {total }}$ is the total current of the electrolysis. The molar quantities of solution-phase products were quantified by NMR spectroscopy and then converted to Coulombs by multiplying by $n F$, where $F$ is Faraday's constant and $n=2,8,12$, and 18 for formate $\left(\mathrm{HCOO}^{-}\right)$, 
acetate $\left(\mathrm{AcO}^{-}\right)$, ethanol (EtOH), and $n$-propanol $(\mathrm{PrOH})$, respectively. The charges corresponding to each product were then compared to the integrated electrolysis charge to determine the Faradaic efficiency.

The partial current density for $\mathrm{CO}_{2} \mathrm{RR}\left(\mathrm{CO}_{2} \mathrm{RR}\right)$ was calculated using the following equation:

$$
j_{\mathrm{CO}_{2} \mathrm{RR}}=\frac{\sum_{\mathrm{CO}_{2} \mathrm{RR} \text { products }}\left(I_{\text {total }} \times \mathrm{FE}\right)}{\text { Electrode area }},
$$

where FE is the Faradaic efficiency of each product, and electrode area is the effective geometrical area of the working electrode.

The single-pass conversion rate $(\mathrm{CR})$ of $\mathrm{CO}_{2}$ was calculated using the following equation:

$$
\mathrm{CR}=\frac{\sum_{\mathrm{CO}_{2} \mathrm{RR} \text { products }}\left(\frac{I_{\text {total }} \times \mathrm{FE}}{n F} \times N_{\mathrm{C}} \times \frac{R T}{P}\right)}{\mathrm{CO}_{2} \text { flow rate }},
$$

where $N_{\mathrm{C}}$ is the number of carbon atoms in each product molecule (for example, $N_{\mathrm{C}}=2$ for $\left.\mathrm{C}_{2} \mathrm{H}_{4}\right), R$ is the ideal gas constant, and $T$ and $P$ are the absolute temperature and pressure of the $\mathrm{CO}_{2}$ gas.

The reported $\mathrm{CO}_{2} \mathrm{RR}$ current densities, Faradaic efficiencies, conversion rates, and their error bars were determined based on the measurements of three separately prepared samples under the same conditions.

\section{Data availability}

The data that support the findings of this study are available in the article and its Supplementary Information file or from the corresponding authors upon reasonable request.

Received: 22 May 2020; Accepted: 23 November 2020; Published online: 08 January 2021

\section{References}

1. Chu, S. \& Majumdar, A. Opportunities and challenges for a sustainable energy future. Nature 488, 294-303 (2012).

2. Weber, R. S. Effective use of renewable electricity for making renewable fuels and chemicals. ACS Catal. 9, 946-950 (2018).

3. De Luna, P. et al. What would it take for renewably powered electrosynthesis to displace petrochemical processes? Science 364, eaav3506 (2019).

4. Hori, Y. in Modern Aspects of Electrochemistry, Vol. 42 (Vayenas, C. G., White, R. E. \& Gamboa-Aldeco, M. E. eds) 89-189 (Springer, New York, 2008).

5. Whipple, D. T. \& Kenis, P. J. Prospects of $\mathrm{CO}_{2}$ utilization via direct heterogeneous electrochemical reduction. J. Phys. Chem. Lett. 1, 3451-3458 (2010).

6. Li, C. W. \& Kanan, M. W. $\mathrm{CO}_{2}$ reduction at low overpotential on $\mathrm{Cu}$ electrodes resulting from the reduction of thick $\mathrm{Cu}_{2} \mathrm{O}$ films. J. Am. Chem. Soc. 134, 7231-7234 (2012)

7. Lu, Q. et al. A selective and efficient electrocatalyst for carbon dioxide reduction. Nat. Commun. 5, 3242 (2014).

8. Wu, Y., Jiang, Z., Lu, X., Liang, Y. \& Wang, H. Domino electroreduction of $\mathrm{CO}_{2}$ to methanol on a molecular catalyst. Nature 575, 639-642 (2019).

9. Ross, M. B. et al. Designing materials for electrochemical carbon dioxide recycling. Nat. Catal. 2, 648-658 (2019).

10. Li, C. W., Ciston, J. \& Kanan, M. W. Electroreduction of carbon monoxide to liquid fuel on oxide-derived nanocrystalline copper. Nature 508, 504-507 (2014).

11. Seh, Z. W. et al. Combining theory and experiment in electrocatalysis: insights into materials design. Science 355, eaad4998 (2017)

12. Wang, J. et al. Ambient ammonia synthesis via palladium-catalyzed electrohydrogenation of dinitrogen at low overpotential. Nat. Commun. 9, 1795 (2018).

13. Montoya, J. H., Peterson, A. A. \& Nørskov, J. K. Insights into C-C Coupling in $\mathrm{CO}_{2}$ electroreduction on copper electrodes. ChemCatChem 5, 737-742 (2013).

14. Garza, A. J., Bell, A. T. \& Head-Gordon, M. Mechanism of $\mathrm{CO}_{2}$ reduction at copper surfaces: pathways to $C_{2}$ products. ACS Catal. 8, 1490-1499 (2018).

15. Garg, S. et al. Advances and challenges in electrochemical $\mathrm{CO}_{2}$ reduction processes: an engineering and design perspective looking beyond new catalyst materials. J. Mater. Chem. A 8, 1511-1544 (2020).

16. Tan, Y. C., Lee, K. B., Song, H. \& Oh, J. Modulating local $\mathrm{CO}_{2}$ concentration as a general strategy for enhancing $\mathrm{C}-\mathrm{C}$ coupling in $\mathrm{CO}_{2}$ electroreduction. Joule 4, 1104-1120 (2020).

17. Bard, A. J. \& Faulkner, L. R. Electrochemical Methods: Fundamentals and Applications 2nd edn, 30 (Wiley, New York, NY, 2001).

18. Zhang, B. A., Ozel, T., Elias, J. S., Costentin, C. \& Nocera, D. G. Interplay of homogeneous reactions, mass transport, and kinetics in determining selectivity of the reduction of $\mathrm{CO}_{2}$ on Gold electrodes. ACS Cent. Sci. $\mathbf{5}$, 1097-1105 (2019).

19. $\mathrm{Ma}$, S. et al. One-step electrosynthesis of ethylene and ethanol from $\mathrm{CO}_{2}$ in an alkaline electrolyzer. J. Power Sources 301, 219-228 (2016).

20. Kim, B., Hillman, F., Ariyoshi, M., Fujikawa, S. \& Kenis, P. J. Effects of composition of the micro porous layer and the substrate on performance in the electrochemical reduction of $\mathrm{CO}_{2}$ to CO. J. Power Sources 312, 192-198 (2016).

21. Dinh, C. T. et al. $\mathrm{CO}_{2}$ electroreduction to ethylene via hydroxide-mediated copper catalysis at an abrupt interface. Science 360, 783-787 (2018).

22. De Arquer, F. P. G. et al. $\mathrm{CO}_{2}$ electrolysis to multicarbon products at activities greater than $1 \mathrm{~A} \mathrm{~cm}^{-2}$. Science 367, 661-666 (2020).

23. Higgins, D., Hahn, C., Xiang, C., Jaramillo, T. F. \& Weber, A. Z. Gas-diffusion electrodes for carbon dioxide reduction: A new paradigm. ACS Energy Lett. 4 , 317-324 (2019).

24. Ren, S. et al. Molecular electrocatalysts can mediate fast, selective $\mathrm{CO}_{2}$ reduction in a flow cell. Science 365, 367-369 (2019).

25. Zheng, T. et al. Large-scale and highly selective $\mathrm{CO}_{2}$ electrocatalytic reduction on nickel single-atom catalyst. Joule 3, 265-278 (2019).

26. Han, L., Zhou, W. \& Xiang, C. High-rate electrochemical reduction of carbon monoxide to ethylene using Cu-nanoparticle-based gas diffusion electrodes. ACS Energy Lett. 3, 855-860 (2018).

27. Jouny, M., Luc, W. \& Jiao, F. High-rate electroreduction of carbon monoxide to multi-carbon products. Nat. Catal. 1, 748-755 (2018).

28. Ripatti, D. S., Veltman, T. R. \& Kanan, M. W. Carbon monoxide gas diffusion electrolysis that produces concentrated $\mathrm{C}_{2}$ products with high single-pass conversion. Joule 3, 240-256 (2019).

29. Burdyny, T. \& Smith, W. A. $\mathrm{CO}_{2}$ reduction on gas-diffusion electrodes and why catalytic performance must be assessed at commercially-relevant conditions. Energy Environ. Sci. 12, 1442-1453 (2019).

30. Weng, L. C., Bell, A. T. \& Weber, A. Z. Modeling gas-diffusion electrodes for $\mathrm{CO}_{2}$ reduction. Phys. Chem. Chem. Phys. 20, 16973-16984 (2018).

31. Leonard, M. E., Clarke, L. E., Forner-Cuenca, A., Brown, S. M. \& Brushett, F R. Investigating electrode flooding in a flowing electrolyte, gas-fed carbon dioxide electrolyzer. ChemSusChem 13, 400-411 (2020).

32. Kas, R. et al. Electrochemical $\mathrm{CO}_{2}$ reduction on nanostructured metal electrodes: fact or defect? Chem. Sci. 11, 1738-1749 (2020).

33. $\mathrm{Li}, \mathrm{J}$. et al. Efficient electrocatalytic $\mathrm{CO}_{2}$ reduction on a three-phase interface. Nat. Catal. 1, 592-600 (2018).

34. Wakerley, D. et al. Bio-inspired hydrophobicity promotes $\mathrm{CO}_{2}$ reduction on a Cu surface. Nat. Mater. 18, 1222-1227 (2019).

35. Li, J. et al. Effectively increased efficiency for electroreduction of carbon monoxide using supported polycrystalline copper powder electrocatalysts. ACS Catal. 9, 4709-4718 (2019).

36. Chen, R. et al. Highly selective production of ethylene by the electroreduction of carbon monoxide. Angew. Chem. Int. Ed. 59, 154-160 (2020).

37. Cai, Z. et al. Selectivity regulation of $\mathrm{CO}_{2}$ electroreduction through contact interface engineering on superwetting $\mathrm{Cu}$ nanoarray electrodes. Nano Res. 12 345-349 (2019).

38. Wang, Y. et al. Rational design of three-phase interfaces for electrocatalysis. Nano Res. 12, 2055-2066 (2019).

39. Eilert, A., Roberts, F. S., Friebel, D. \& Nilsson, A. Formation of copper catalysts for $\mathrm{CO}_{2}$ reduction with high ethylene/methane product ratio investigated with in situ X-ray absorption spectroscopy. J. Phys. Chem. Lett. 7, 1466-1470 (2016).

40. Steitz, R. et al. Nanobubbles and their precursor layer at the interface of water against a hydrophobic substrate. Langmuir 19, 2409-2418 (2003).

41. Zhang, X. H., Quinn, A. \& Ducker, W. A. Nanobubbles at the interface between water and a hydrophobic solid. Langmuir 24, 4756-4764 (2008).

42. Burdyny, T. et al. Nanomorphology-enhanced gas-evolution intensifies $\mathrm{CO}_{2}$ reduction electrochemistry. ACS Sustain. Chem. Eng. 5, 4031-4040 (2017).

43. Zhao, X., Ren, H. \& Luo, L. Gas bubbles in electrochemical gas evolution reactions. Langmuir 35, 5392-5408 (2019).

44. Perez Sirkin, Y. A., Gadea, E. D., Scherlis, D. A. \& Molinero, V. Mechanisms of nucleation and stationary states of electrochemically generated nanobubbles. J. Am. Chem. Soc. 141, 10801-10811 (2019).

45. Liu, X. et al. pH effects on the electrochemical reduction of $\mathrm{CO}_{2}$ towards $\mathrm{C}_{2}$ products on stepped copper. Nat. Commun. 10, 32 (2019).

46. Waszczuk, P., Zelenay, P. \& Sobkowski, J. Surface interaction of benzoic acid with a copper electrode. Electrochim. Acta 40, 1717-1721 (1995).

47. O’Brien, T. F., Bommaraju, T. V. \& Hine, F. Handbook of Chlor-Alkali Technology Vol. 1 (Springer, Boston, MA, 2005).

48. Kreutzer, H., Yarlagadda, V. \& Van Nguyen, T. Performance evaluation of a regenerative hydrogen-bromine fuel cell. J. Electrochem. Soc. 159, F331-F337 (2012).

49. Bisquert, J., Garcia-Belmonte, G., Fabregat-Santiago, F. \& Bueno, P. R. Theoretical models for ac impedance of finite diffusion layers exhibiting low frequency dispersion. J. Electroanal. Chem. 475, 152-163 (1999). 
50. Kwon, W., Kim, J. M. \& Rhee, S. W. A new equivalent circuit model for porous carbon electrodes in charge transfer reaction of iodide/triiodide redox couples. Electrochim. Acta 68, 110-113 (2012).

51. Zhang, W. et al. Investigations on the interfacial capacitance and the diffusion boundary layer thickness of ion exchange membrane using electrochemical impedance spectroscopy. J. Membr. Sci. 502, 37-47 (2016).

52. Ringe, $\mathrm{S}$. et al. Double layer charging driven carbon dioxide adsorption limits the rate of electrochemical carbon dioxide reduction on Gold. Nat. Commun. 11, 33 (2020).

53. Resasco, J. et al. Promoter effects of alkali metal cations on the electrochemical reduction of carbon dioxide. J. Am. Chem. Soc. 139, 11277-11287 (2017)

54. Dunwell, M., Yan, Y. \& Xu, B. Understanding the influence of the electrochemical double-layer on heterogeneous electrochemical reactions. Curr. Opin. Chem. Eng. 20, 151-158 (2018).

55. Wang, Q., Dong, H., Yu, H. \& Yu, H. Enhanced performance of gas diffusion electrode for electrochemical reduction of carbon dioxide to formate by adding polytetrafluoroethylene into catalyst layer. J. Power Sources 279, 1-5 (2015).

56. Inoue, G., Matsukuma, Y. \& Minemoto, M. Effect of gas channel depth on current density distribution of polymer electrolyte fuel cell by numerical analysis including gas flow through gas diffusion layer. J. Power Sources 157, 136-152 (2006).

57. Clark, E. L. et al. Standards and protocols for data acquisition and reporting for studies of the electrochemical reduction of carbon dioxide. ACS Catal. 8, 6560-6570 (2018).

58. Hu, L., Xing, Z. \& Feng, X. Understanding the electrocatalytic interface for ambient ammonia synthesis. ACS Energy Lett. 5, 430-436 (2020).

59. Ravel, B. \& Newville, M. ATHENA, ARTEMIS, HEPHAESTUS: data analysis for X-ray absorption spectroscopy using IFEFFIT. J. Synchrotron Radiat. 12, 537-541 (2005).

60. Bondarenko, A. S. \& Ragoisha, G. A. in Progress in Chemometrics Research (ed. Pomerantsev, A. L.) 89-102 (Nova Science Publishers, New York, NY, 2005).

\section{Acknowledgements}

This work was supported by a startup fund from the University of Central Florida and a Sloan Research Fellowship from the Alfred P. Sloan Foundation (Grant Number: FG2019-11694). The authors acknowledge the use of an XPS instrument supported by the NSF MRI: ECCS: 1726636. Use of the Stanford Synchrotron Radiation Lightsource, SLAC National Accelerator Laboratory, is supported by the U.S. Department of Energy, Office of Science, Office of Basic Energy Sciences under Contract No. DE-AC02-76SF00515.

\section{Author contributions}

Z.X. and X.F. designed the experiments. Z.X. prepared the GDE cell, performed the experiments, and analyzed the data. L.H. assisted in the experimental work. D.S.R. provided the design of the GDE cell and helpful discussions. X.F., Z.X., and X.H. cowrote the manuscript. X.F. and X.H. supervised the work. All authors discussed the results and commented on the manuscript.

\section{Competing interests}

The authors declare no competing interests.

\section{Additional information}

Supplementary information is available for this paper at https://doi.org/10.1038/s41467020-20397-5.

Correspondence and requests for materials should be addressed to X.H. or X.F.

Peer review information Nature Communications thanks Tierui Zhang and the other, anonymous, reviewer(s) for their contribution to the peer review of this work.

Reprints and permission information is available at http://www.nature.com/reprints

Publisher's note Springer Nature remains neutral with regard to jurisdictional claims in published maps and institutional affiliations.

(c) (i) Open Access This article is licensed under a Creative Commons Attribution 4.0 International License, which permits use, sharing, adaptation, distribution and reproduction in any medium or format, as long as you give appropriate credit to the original author(s) and the source, provide a link to the Creative Commons license, and indicate if changes were made. The images or other third party material in this article are included in the article's Creative Commons license, unless indicated otherwise in a credit line to the material. If material is not included in the article's Creative Commons license and your intended use is not permitted by statutory regulation or exceeds the permitted use, you will need to obtain permission directly from the copyright holder. To view a copy of this license, visit http://creativecommons.org/ licenses/by/4.0/.

(C) The Author(s) 2021 